\section{Avaliação da vestimenta utilizada como equipamento de proteção individual pelos aplicadores de malationa no controle da dengue em São Paulo, Brasil}

\author{
Evaluation of personal protective equipment \\ used by malathion sprayers in dengue control \\ in São Paulo, Brazil
}

\section{Evaluación de la vestimenta utilizada como equipo de protección personal por los fumigadores de malathion en el control del dengue en São Paulo, Brasil}

Thais Salomão Leme 1 Solange Papini 2 Eliane Vieira 1 Luiz Carlos Luchini 1

\footnotetext{
${ }^{1}$ Instituto Biológico, São Paulo, Brasil.

2 Coordenação de Vigilância em Saúde, Secretaria Municipal de Saúde de São Paulo, São Paulo, Brasil.

Correspondência T. S. Leme Instituto Biológico. Av. Conselheiro Rodrigues Alves 1252, São Paulo, SP 04014-002, Brasil. thathasalomao@hotmail.com
}

\begin{abstract}
Malathion insecticide in vegetable oil is used to control Aedes aegypti and is applied by spraying, which requires the use of personal protective equipment (PPE). The current study assessed the capacity of PPE suits to retain malathion. The study monitored field spraying in São Paulo, Brazil. Before each spraying, feminine sanitary napkins were placed under and upon the PPE suit in the chest, back, and forearms. After spray ing, the sanitary napkins were removed, labeled, and submitted to extraction under mechanical agitation. The extracts were analyzed by gas chromatography with a flame ionization detector. Presence of malathion in sanitary napkins under PPE suits was observed after spraying and before washing the suits. The findings indicate that sprayers are exposed to malathion, even when they use new PPE suits.
\end{abstract}

Protective Devices; Organophosphate Insecticides; Aedes aegypti; Vector Control

\section{Resumo}

O inseticida malationa em calda oleosa é utilizado no controle do Aedes aegypti e a sua aplicação é feita por meio de nebulização. Essa atividade exige o uso de equipamento de proteção individual (EPI) pelos aplicadores. Este trabalho avaliou a capacidade de retenção do inseticida malationa nas vestimentas do EPI após nebulização em campo. Foram acompanhadas nebulizações em campo, realizadas pelos agentes de zoonoses, na cidade de São Paulo, Brasil. Antes de cada nebulização eram colocados absorventes sob e sobre a vestimenta do EPI no tórax, na face superior da parede torácica (costas) e nos antebraços. Após cada aplicação, os absorventes eram retirados, identificados e submetidos à extração sob agitação mecânica. Os extratos foram analisados por cromatografia a gás com detector de ionização de chama. Observou-se a presença de malationa nos absorventes sob as vestimentas do EPI já na primeira aplicação, antes da lavagem. Os resultados indicam que os agentes, nas condições avaliadas, estão expostos ao malationa, mesmo com uso de vestimentas de EPI novos.

Equipamentos de Proteção; Inseticidas

Organofosforados; Aedes aegypti;

Controle de Vetores 


\section{Introdução}

A dengue é atualmente uma das principais endemias no Brasil 1, o controle dessa doença baseiase, principalmente, na orientação da população quanto aos cuidados para se evitar a proliferação do mosquito vetor e no manejo do ambiente 2, mas em determinadas situações recorre-se à aplicação de inseticidas. Em São Paulo, e em muitas outras cidades do país, quando há caso confirmado da doença utiliza-se o inseticida organofosforado malationa grau técnico (GT) 96\% diluído em óleo vegetal (1:2 v/v) para formar a calda de aplicação usada no controle do mosquito adulto ${ }^{1}$. Esse inseticida atua como inibidor da acetilcolinesterase 3,4 , apresenta baixa toxicidade aguda para mamíferos 5 e possui baixa persistência no ambiente 6 . A aplicação da calda de malationa é feita por meio de nebulização, com liberação de pequenas gotículas que ficam em suspensão no ar por um período de tempo, sendo uma metodologia eficaz para controle do mosquito adulto alado 7. É importante destacar que a maior via de contaminação em aplicadores de agrotóxicos é a dérmica, correspondendo a mais de $99 \%$ da exposição total ${ }^{8}$, seguido da via inalatória. Assim, o uso de equipamento de proteção individual (EPI), constituído por um conjunto composto por calça, blusa de manga longa, jaleco costal, boné tipo touca árabe e avental, além de botas, luvas e máscaras com filtro, é uma medida importante durante a realização da nebulização, bem como nos demais procedimentos como, por exemplo, na preparação da calda 1 , pois serve de barreira para a entrada da substância no organismo, colaborando para evitar contaminações e consequentes intoxicações 9. Para assegurar a eficácia do EPI e garantir a proteção do agente de zoonoses, a manutenção constante e limpeza da vestimenta, máscaras, botas e luvas, por meio de lavagem, devem ser feitas após cada aplicação. Entretanto, os procedimentos de aplicação do inseticida e limpeza do EPI podem expor os agentes de zoonoses a resíduos tóxi$\cos 10$. Estudos para avaliar a exposição e a proteção oferecida pelas vestimentas do EPI no Brasil foram iniciados recentemente e têm sido de grande importância, uma vez que analisam as condições locais de exposição e podem auxiliar em normas e ensaios específicos de acordo com a necessidade do país. As exposições dos trabalhadores aos agrotóxicos ocorrem na saúde pública, em empresas desinsetizadoras, durante a produção desses produtos e principalmente na agricultura 11 , e portanto, se verifica a maior parte dos estudos para esse setor.

O uso de EPI nas atividades com agrotóxicos é indispensável desde a preparação da calda até a lavagem dos equipamentos e maquinários utilizados durante a atividade 1,12, entretanto, o EPI não evita totalmente a exposição do trabalhador 9,13, outro fator importante é que a utilização incorreta também pode se tornar um risco para a saúde dos trabalhadores 9 .

As informações sobre uso e manutenção devem ser constantes e adequadas para a realidade dos trabalhadores 9. Veiga et al. ${ }^{9}$ apresentaram um estudo sobre a contaminação por agrotóxico em viticultura onde os trabalhadores foram contaminados pelo uso incorreto do EPI, e Oliveira \& Machado Neto ${ }^{14}$ observaram a exposição dérmica de trabalhadores rurais mesmo com a utilização de EPI. Outra questão a ser destacada é a real remoção dos insumos tóxicos do EPI por meio da lavagem. Davies et al. 15 e Clifford \& Nies 16 apresentaram diferentes trabalhos onde demostram que a lavagem não remove totalmente os agrotóxicos e pode ser uma fonte de contaminação.

Diante disso, este trabalho avaliou a capacidade de retenção do ingrediente ativo malationa na vestimenta do EPI utilizado para o controle da dengue. A avaliação da capacidade de retenção do ingrediente ativo no EPI durante a aplicação é necessária para verificar se o composto está migrando para a pele e é uma medida de prevenção que deve ser realizada visando evitar danos à saúde do trabalhador.

\section{Material e métodos}

O padrão analítico do malationa, com pureza química superior a 99\%, obtido da Chemservice (West Chester, Estados Unidos), foi utilizado para o estabelecimento da metodologia analítica e o malationa grau técnico $96 \%$ foi utilizado nos testes de campo. A quantificação do ingrediente ativo malationa foi determinada em cromatografia a gás, com padronização externa, em equipamento Shimadzu, modelo GC-2014AFsc (Shimadzu Corp., Tóquio, Japão), equipado com detector de ionização de chama. As amostras foram injetadas por meio de injetor automático no modo split (1/1). A temperatura do injetor foi de $230^{\circ} \mathrm{C}$ e a do detector, $300^{\circ} \mathrm{C}$. A temperatura da coluna foi de $60^{\circ} \mathrm{C}$, mantida por 1 minuto; aumento na taxa de $25^{\circ} \mathrm{C}$ por minuto até $250^{\circ} \mathrm{C}$; mantido por 3 minutos; aumento de $30^{\circ} \mathrm{C}$ por minuto até $280^{\circ} \mathrm{C}$ e mantido nesta temperatura por 5 minutos. Uma coluna capilar RTX 5 (30,0m x 0,25mm x 0,25um) foi utilizada e o nitrogênio foi o gás de arraste a um fluxo de 1,44mL.min ${ }^{-1}$ sob pressão constante.

O estudo foi observacional, foram acompanhadas nebulizações desenvolvidas rotineiramente para o controle do Aedes aegypti realizadas 
pelas equipes da Vigilância em Saúde Ambiental da Supervisão de Vigilância em Saúde de Campo Limpo (SUVIS Campo Limpo), Município de São Paulo, Brasil, ou seja, em situação real de campo. Salienta-se que não houve interferência na rotina do procedimento realizado pela unidade, desenvolvendo-se conforme o preconizado pelos programas federal, estadual e municipal. $\mathrm{Na}$ rotina do procedimento de nebulização dois funcionários participaram diretamente, um "aplicador" que carregava o equipamento nebulizador e fazia a aplicação do inseticida e um "apoio (ao aplicador)" para ajudar no caso de algum incidente, estando sujeitos às mesmas condições de aplicação. Além do aplicador e do apoio, outros funcionários ("batedores”), em número variável dependendo da área, também participaram da operação, avisando e orientando a população que se encontrava nas edificações sobre o procedimento a ser realizado, permanecendo próximos aos munícipes durante a atividade. Esses agentes, embora capacitados pela SUVIS Campo Limpo, foram informados que seriam acompanhados durante as atividades e que o estudo visava avaliar a capacidade de retenção da vestimenta. Antes do início do estudo foram realizadas palestras e discussões com o grupo de modo a esclarecer sobre a finalidade do estudo, com destaque ao fato de que seriam feitas análises do material usado para captação do malationa e que não seria avaliada a real concentração do inseticida que poderia estar sendo absorvida pelo organismo. Foram acompanhadas nebulizações de rotina durante três semanas: semana 1 (S1) - 28 de fevereiro de 2012 a 4 de março de 2012; semana 2 (S2) - 14 de março de 2012 a 18 de março de 2012 e semana 3 (S3) - 9 de maio de 2012 a 13 de maio de 2012. Foram usados EPI reutilizáveis novos de duas marcas, ambas com o certificado de aprovação emitido pela Secretaria de Segurança e Saúde do Trabalhador ligada ao Ministério do Trabalho e Emprego, por cinco dias consecutivos, sendo que as vestimentas eram lavadas e secas após cada uso. Nas semanas S1 e S2 foi utilizada a vestimenta de EPI AZ Brasil, modelo kit costal alumínio, lote 002029 (EPI AZ Brasil, Andradas, Brasil), e na semana S3 utilizou-se a vestimenta do EPI modelo Agro 500 fornecido pela SUVIS Campo Limpo (R\&B Equipamentos de Segurança, Londrina, Brasil). Também foi acompanhada uma nebulização em campo realizada pela SUVIS Campo Limpo, na qual os funcionários usaram EPI descartável, Coverall CE 0120 Drager Categoria 3, DTex macrobond (Drager, Lübeck, Alemanha). No caso do EPI descartável, a vestimenta constituía-se de um macacão inteiriço, inclusive com touca, confeccionado de material revestido com polietileno.
A avaliação da presença de malationa foi realizada a partir dos absorventes higiênicos femininos 17 Carefree (Johnson \& Johnson, São Paulo, Brasil) colocados entre a roupa do aplicador e a vestimenta do EPI (absorventes internos) na parede toráxica anterior dos lados direito e esquerdo; antebraço direito e esquerdo; na face súperoposterior da parede torácica logo abaixo da região cervical posterior e na face súpero-posterior da parede torácica direita e esquerda colocados em posição vertical, um a cada lado, em posição superior e lateral às escápulas (Figura 1). Os absorventes externos foram colocados da mesma forma, mas, externamente à vestimenta do EPI. É importante destacar que os absorventes colocados externamente não ficavam sobrepostos aos absorventes internos, perfazendo um total de 239 absorventes internos e externos analisados nas três semanas de estudo, sendo que em cada dia eram analisados sete absorventes internos e sete absorventes externos. Uma amostra de absorvente posicionada no antebraço interno esquerdo na S2 foi perdida durante a análise por isso o total de analises não foi de 240.

A colocação do EPI e dos absorventes pelo aplicador era realizada na SUVIS Campo Limpo. Já a remoção dos absorventes higiênicos femininos e a retirada dos EPI contaminados eram feitas no local após o término do procedimento de nebulização, de modo a evitar uma possível contaminação do veículo usado para o transporte dos agentes.

Diariamente, após a nebulização os absorventes higiênicos femininos eram retirados, identificados, levados para o laboratório e guardados em freezer a $-25^{\circ} \mathrm{C}$. As vestimentas dos EPI reutilizáveis eram lavadas após cada nebulização em máquinas de lavar roupa, e secas em secadora, na SUVIS Campo Limpo, para utilização no dia seguinte.

Para a extração do malationa, os absorventes higiênicos femininos foram submetidos à agitação mecânica por 30 minutos com $60 \mathrm{~mL}$ de hexano e os extratos analisados em cromatógrafo a gás modelo GC-2014AFsc (Shimadzu Corp., Tóquio, Japão) nas condições analíticas previamente descritas.

Foi aplicado o teste qui-quadrado (g.l. = 2; $\alpha=0,05)$ para detectar a existência de possível diferença no grau de exposição em função da localização do absorvente na parede toráxica anterior (frente), direita ou esquerda; face superior da parede toráxica (costas), direita ou esquerda; e antebraço direito ou esquerdo. Para isso avaliouse a frequência de malationa nos absorventes higiênicos internos comparando-se os pares de absorventes, externo e interno, dispostos na parede torácica anterior (frente), na face superior 

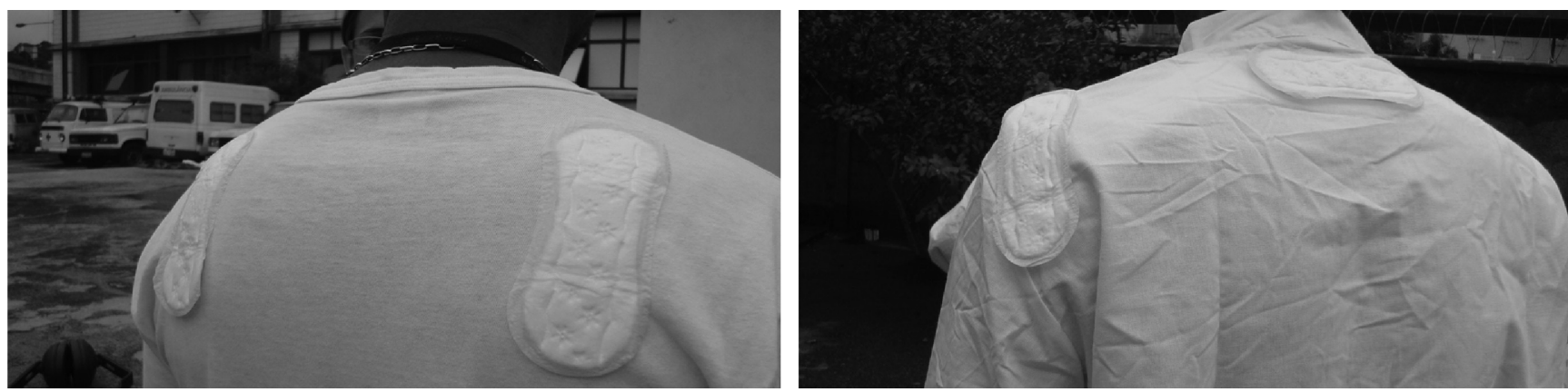

1c)

1d)
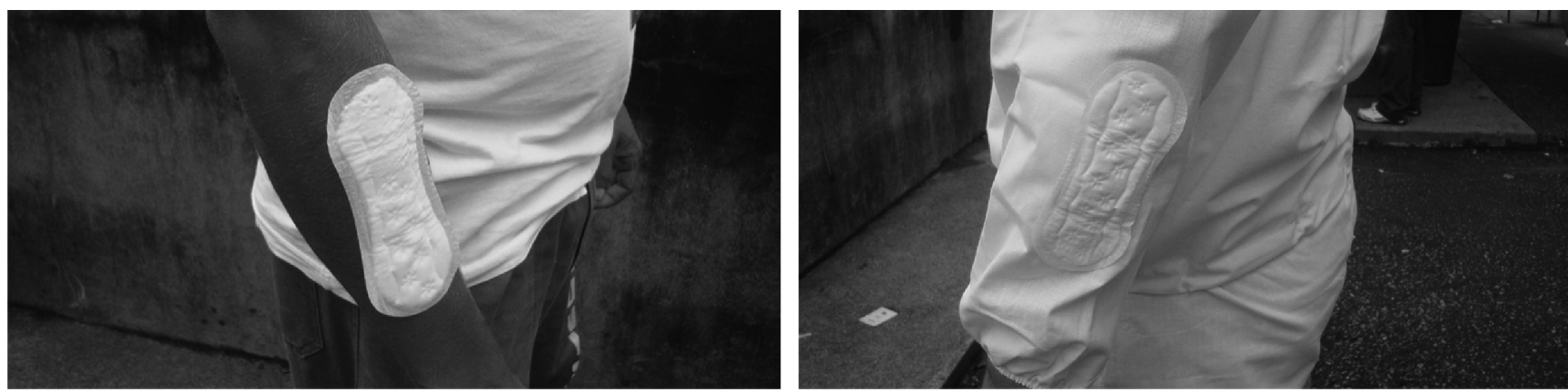

da parede torácica (costas) e nos antebraços do aplicador.

A penetração do malationa através da vestimenta foi calculada de acordo com a fórmula: porcentagem de penetração de malationa = (concentração interna $\div$ concentração externa) $\mathrm{x} 100$.

A capacidade de retenção do ingrediente ativo na vestimenta do EPI foi calculada a partir dos resultados obtidos pelo cálculo da porcentagem de penetração segundo a fórmula: capacidade de retenção $=100-[($ concentração interna $\div$ concentração externa) x 100].

\section{Resultados}

As curvas analíticas para quantificação do malationa foram estabelecidas por análise de regres- são linear com limite de 95\% de confiança e apresentaram linearidade nas faixas de concentração de 1,54 a $23,32 \mu \mathrm{g} \cdot \mathrm{mL}^{-1}$ e de 19,6 a $326,78 \mu \mathrm{g} \cdot \mathrm{mL}^{-1}$, com coeficiente de correlação (r) de 0,99 e coeficiente de determinação ( $\left.\mathrm{r}^{2}\right)$ de 0,99. O tempo de retenção cromatográfica da malationa foi de 8,8 minutos nas condições apresentadas. A presença de malationa nos absorventes foi tratada com sim/não e quantificadas em cromatografia gasosa de acordo com os parâmetros acima estabelecidos.

As condições climáticas estavam favoráveis nas semanas de nebulização, com temperaturas variando entre $18^{\circ} \mathrm{C}$ e $25^{\circ} \mathrm{C}$ e velocidade do vento inferior a $6 \mathrm{~m} . \mathrm{s}^{-1}$. Os agentes realizaram a nebulização por cerca de 4 horas, iniciando o procedimento entre 09:30 e 10:00 e terminando entre 13:30 e 14:00. O volume de calda usada em campo nas três semanas variou entre as nebulizações 
de 1,0 a 3,0L, sendo que nos dias 18 de março, 10, 11,12 e 13 de maio o volume foi menor, utilizando-se respectivamente $0,20 \mathrm{~L} ; 0,30 \mathrm{~L} ; 0,70 \mathrm{~L} ; 0,70 \mathrm{~L}$ e $0,70 \mathrm{~L}$ de calda. Essa variação está relacionada com a área dos locais que foram nebulizados, que apresentavam dimensões distintas.

Nas Figuras 2 e 3 são apresentados os resultados de malationa encontrados nos 239 absorventes (externos e internos), colocados nas vestimentas dos EPI reutilizáveis.

Os resultados demonstram que não houve a retenção do inseticida pela vestimenta de EPI, independente da marca a vestimenta do EPI. A passagem de malationa foi observada nos absorventes higiênicos femininos internos antes de a roupa ser submetida à primeira lavagem.

A porcentagem de absorventes higiênicos femininos colocados sob a vestimenta do EPI (absorventes internos) que apresentaram malationa variou de $27 \%$ a $80 \%$ dependendo do local que estava posicionado sendo que a maior porcentagem encontrada estava sob a touca $(80 \%$ das amostras contaminadas com malationa).

Dos absorventes colocados nos antebraços a porcentagem de absorventes contaminados com malationa foi de $73 \%$ no antebraço esquerdo e $53 \%$ no antebraço direito. Na face súperoposterior da parede torácica $47 \%$ das amostras estavam contaminadas do lado direito e $27 \%$ do lado esquerdo. Quanto aos absorventes colocados na parede torácica anterior, o lado direito apresentou malationa em $33 \%$ das amostras e o lado esquerdo $27 \%$. Foi detectado malationa nos absorventes internos à vestimenta em concen-

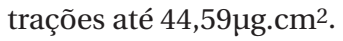

Os resultados mostraram que a penetração do malationa nas semanas S1, S2 e S3, foram de $7,25 \% ; 12,67 \%$ e $6,31 \%$ respectivamente. Complementar à penetração do malationa, os resultados da capacidade de retenção são apresentados na Tabela 1 .

Os absorventes higiênicos femininos colocados sob a vestimenta do EPI descartável também apresentaram malationa na face superior da parede torácica (costas) lado direito, tórax lado direito

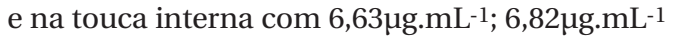
e $9,81 \mu \mathrm{g} \cdot \mathrm{mL}^{-1}$ de malationa respectivamente.

Nas semanas S1 e S2 o número de pares analisados no antebraço foi 19 , na face superior da parede torácica (costas) 20 e no tórax 20, totalizando 59 pares. Constatou-se a presença de malationa em 13 pares nos antebraços, 12 na face superior da parede torácica (costas) e no tórax, 7. A análise estatística mostrou que não houve diferença significativa $(p=0,720)$ na frequência de passagem de malationa para o absorvente

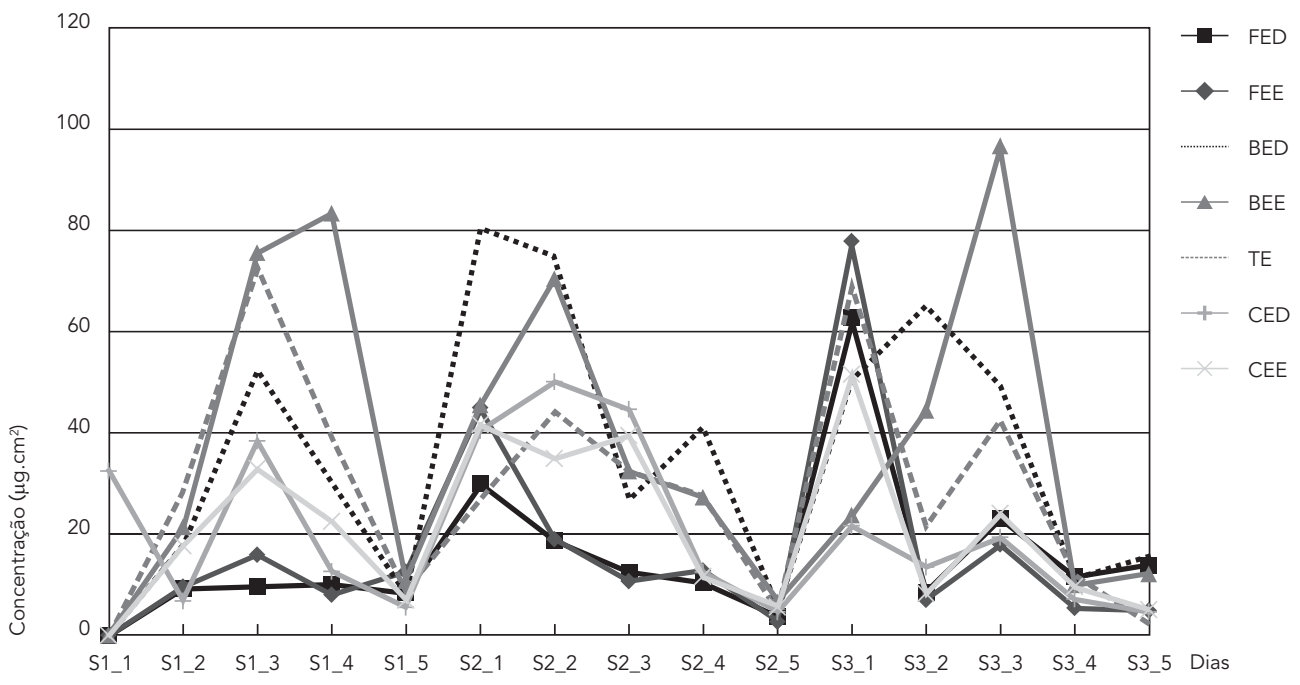

BED: antebraço direito; BEE: antebraço esquerdo; CED: parede toráxica (costas) externo direita; CEE: parede toráxica (costas) externo esquerda; FED: parede torácica anterior lado direito; FEE: parede torácica anterior lado esquerdo; TE: touca externa. 
Resultados do malationa encontrado nos absorventes internos à vestimenta do equipamento de proteção individual.

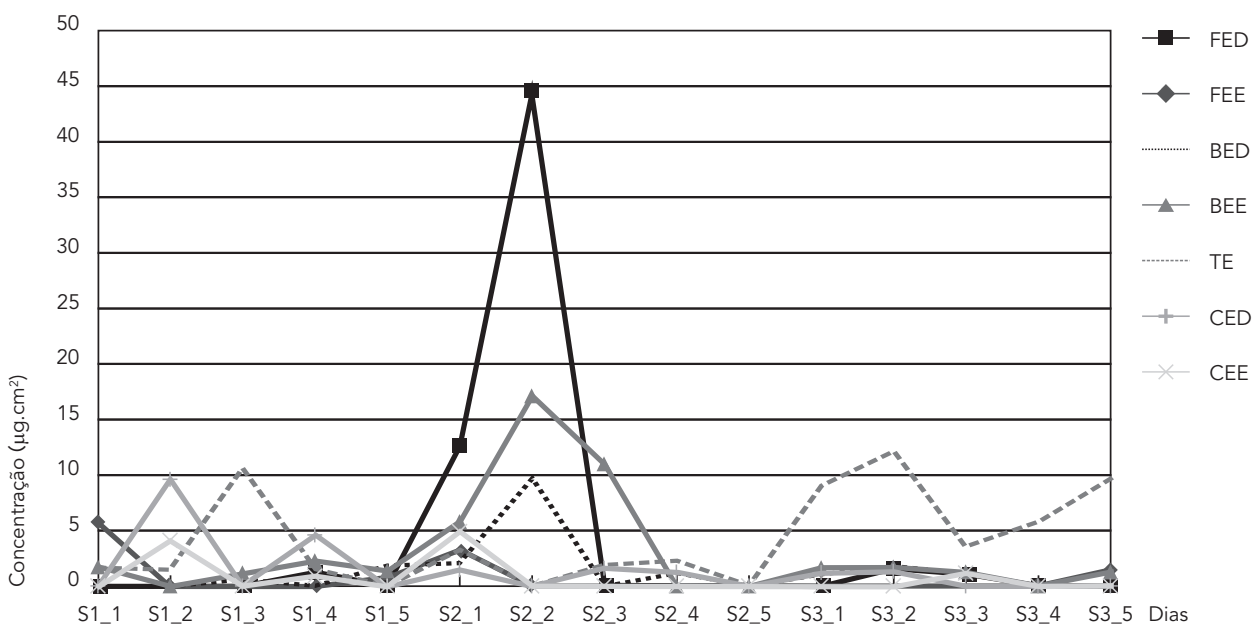

BED: antebraço direito; BEE: antebraço esquerdo; CED: parede toráxica (costas) externo direita; CEE: parede toráxica (costas) externo esquerda; FED: parede torácica anterior lado direito; FEE: parede torácica anterior lado esquerdo; TE: touca externa.

interno entre os pares dispostos no tórax, na face superior da parede torácica (costas) e nos antebraços dos agentes. Nas semanas S1 e S2 o malationa foi quantificado nos absorventes internos em $45,7 \%$ das amostras.

Na S3 foram analisados 30 pares de absorventes, sendo 10 nos antebraços, 10 na face superior da parede torácica (costas) e 10 no tórax, desse total os absorventes dispostos nos antebraços que apresentaram malationa foram 7 , na face superior da parede torácica (costas) 3 e no tórax 3 . O número de pares analisados que apresentaram ou não malationa nos absorventes higiênicos internos, na S3 não apresentou diferença significativa $(p=0,114)$ na frequência de passagem. Nessa semana (S3) 51,4\% dos absorventes internos estavam contaminados.

Esses resultados indicam que a frequência de passagem foi semelhante nestas localizações.

Observou-se que o EPI descartável rasgou durante a aplicação e a touca não foi suficiente para proteger a cabeça do funcionário, deixando assim a região cervical posterior (pescoço), uma parte do rosto e a testa expostas à calda durante a nebulização (Figura 4). A capacidade de retenção do ingrediente ativo na vestimenta desses EPI foi de $91,34 \%$, não diferente do observado para o EPI reutilizável.
Tabela 1

Capacidade de retenção do malationa (\%) na vestimenta do equipamento de proteção individual (EPI).

$\%$

$\begin{array}{cc}\text { Semana } 1 & \\ \text { 28/Fev } & 72 \\ \text { 1/Mar } & 86 \\ \text { 2/Mar } & 96 \\ \text { 3/Mar } & 95 \\ \text { 4/Mar } & 93 \\ \text { Semana 2 } & \\ \text { 14/Mar } & 89 \\ \text { 15/Mar } & 77 \\ \text { 16/Mar } & 92 \\ \text { 17/Mar } & 97 \\ \text { 18/Mar } & 100 \\ \text { Semana 3 } & \\ \text { 9/Mai } & 96 \\ \text { 10/Mai } & 89 \\ \text { 11/Mai } & 97 \\ \text { 12/Mai } & 91 \\ \text { 13/Mai } & 79\end{array}$


4a)

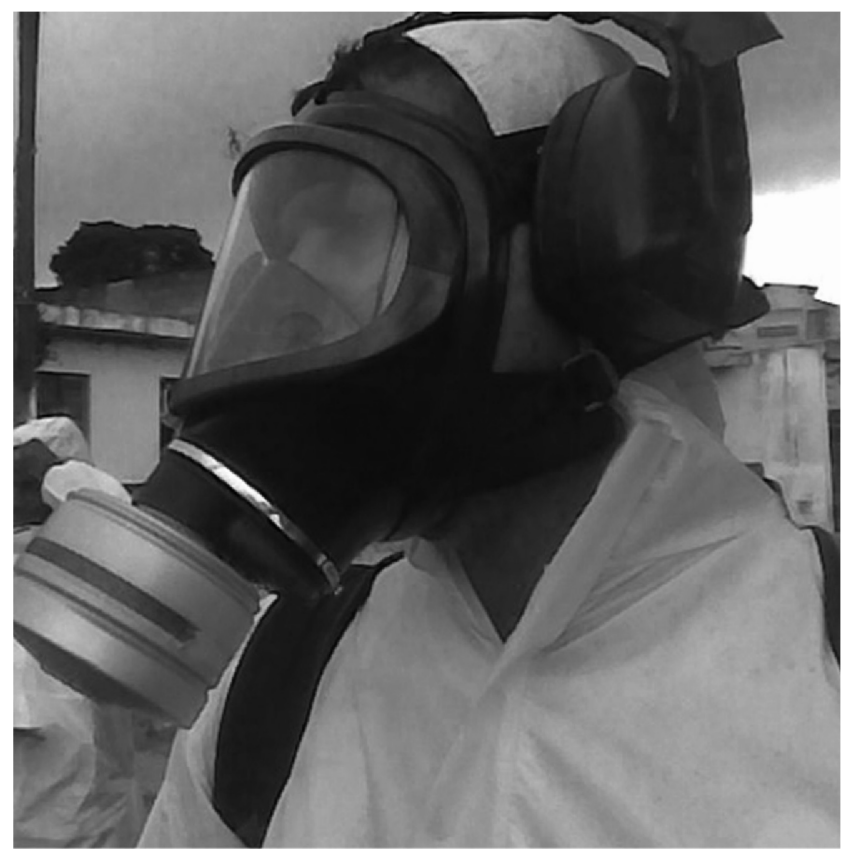

4b)

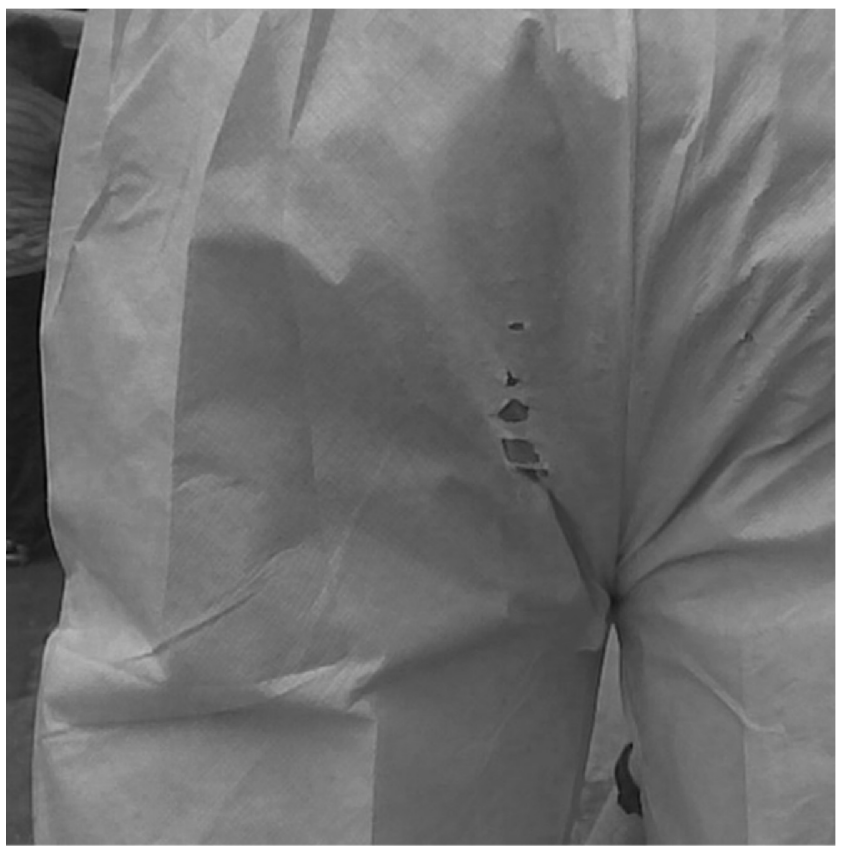

\section{Discussão}

Diante dos resultados obtidos, a vestimenta do EPI não foi capaz de reter o malationa mesmo sendo nova, expondo assim os agentes ao inseticida. Os resultados obtidos no presente trabalho são semelhantes ao encontrados por Botti 8 que também analisou a vestimenta dos EPI utilizados pela Superintendência de Controle de Endemias (SUCEN) nas cidades de Ribeirão Preto e Olímpia (São Paulo) e concluiu que existe exposição dérmica à calda de malationa, portanto, ocorre a passagem desse ingrediente ativo através da vestimenta do EPI. Os resultados encontrados neste trabalho evidenciam que o uso da roupa de proteção não evita a exposição ao inseticida malationa. É importante destacar que em todas as nebulizações em campo os agentes apresentavam intensa transpiração após o término da atividade, possivelmente relacionado ao esforço físico necessário. $\mathrm{O}$ aumento na transpiração, segundo Garrígou et al. ${ }^{13}$, pode contribuir para a penetração da calda através da roupa e favorecer a exposição do trabalhador. Além disso, o suor do corpo fica retido entre a superfície da pele a e vestimenta do EPI formando uma camada de ar quente e úmido, fazendo com que os poros fiquem mais abertos, o que pode facilitar a absorção pela pele 18 aumentando a exposição do trabalhador ao produto químico. Os resultados obtidos nas análises dos absorventes higiênicos femininos colocados na touca interna revelaram que esse tipo de touca pode possibilitar a passagem da névoa de inseticida pelas aberturas laterais, atingindo o absorvente higiênico feminino colocado sob ela.

A variabilidade dos resultados para a capacidade de retenção pode estar relacionada às variáveis da própria atividade e das condições do ambiente de aplicação.

Um aspecto de grande importância é o tempo de nebulização e a quantidade de calda utilizada, pois quanto mais tempo a vestimenta for exposta à calda, maior será o volume depositado sobre ela, o que pode favorecer a penetração do produto. Ainda salienta-se que a movimentação do 
aplicador que está com o equipamento de aplicação pode deslocar a vestimenta facilitando a passagem do produto. Além disso, é importante destacar que diferente do que ocorre na agricultura, as condições urbanas de aplicação são muito variáveis. A aplicação muitas vezes ocorre em vielas, garagens e outros locais onde a circulação do ar é restrita. Esses fatores influenciam diretamente na capacidade de retenção do ingrediente ativo na vestimenta. Os resultados obtidos neste trabalho quanto à capacidade de retenção do ingrediente ativo no EPI confirmam aqueles verificados por Botti ${ }^{8}$. A capacidade de retenção do malationa nas vestimentas usadas para o controle da dengue também foi avaliado por Botti 8 nas cidades de Ribeirão Preto e Olímpia e foi verificado que a vestimenta fornecida pela SUCEN teve a capacidade de retenção de 56,8\% e a vestimenta da Agro Light (R\&B Equipamentos de Segurança, Londrina, Brasil) 95,8\%.

O objetivo deste trabalho não foi avaliar a exposição dérmica dos trabalhadores, o que envolveria outro delineamento experimental, porém, os resultados mostraram que o malationa é encontrado entre a vestimenta do EPI e a roupa do aplicador, o que pode levar à exposição do trabalhador. Entendemos ser necessária a realização de mais estudos para avaliar a real exposição dérmica e os riscos aos trabalhadores, usando procedimentos que permitam a quantificação do risco. Segundo Frenich et al. 19, em trabalho realizado na agricultura em casa de vegetação, os agrotóxicos que são aplicados manualmente expõem os aplicadores a um nível elevado de contaminação dérmica. Assim os autores recomendam a necessidade de se criar programas de monitoramento para avaliação da exposição. Observam ainda que uma das principais variáveis que devem ser levadas em conta em um programa de monitoramento é o tamanho da gota, já que gotas menores que $150 \mu \mathrm{m}$ favorecem a exposição dérmica. Nebulizadores como o utilizado na aplicação do malationa nas atividades de controle do A. aegypti produzem gotas entre $10 \mu \mathrm{m}$ e $20 \mu \mathrm{m} 20$, fato este que possibilita a passagem de gotículas da calda através das vestimentas, o que foi confirmado neste trabalho, pelos resultados positivos encontrados em todas as partes do corpo onde foram dispostos absorventes sob a vestimenta.

Apesar de a touca ser a parte do EPI mais atingida pode-se verificar que ocorreu a passagem do malationa em todos os outros locais analisados. Para avaliar se houve diferença na exposição dos absorventes higiênicos femininos em função de sua localização, analisaram-se os pares de absorventes (externos e internos) e o número de pares que apresentaram ou não malationa nos absorventes higiênicos internos (sob o EPI), utilizan- do-se os absorventes dispostos nos antebraços, face superior da parede torácica (costas) e parede torácica anterior (frente).

Dados de literatura também apontam para a exposição ao agrotóxico mesmo com uso da vestimenta do EPI, além de salientarem que sua reutilização pode ser uma fonte de contaminação 10,13,21, proporcionando assim uma sensação de segurança que não existe. Idealmente espera-se que a vestimenta do EPI minimize a exposição, ou seja, diminua o contato entre o trabalhador e o produto formando uma barreira entre os dois 10 , entretanto os dados obtidos neste trabalho mostraram que essa barreira não foi eficaz, permitindo a passagem de malationa através da vestimenta do EPI desde a primeira aplicação, o que foi observado nas três semanas analisadas, mesmo com o uso da vestimenta do EPI de marcas diferentes e novos sem terem sido submetidos à lavagem prévia. Estes resultados mostram que existe a necessidade urgente de se avaliar os procedimentos para obtenção do certificado de aprovação, pois, talvez os testes que são feitos não garantam a segurança do trabalhador. Normas internacionais estabelecem meios para avaliar a eficácia das vestimentas do EPI contra riscos químicos. A norma ISO 16602:2007 22 e a ISO 27065:2011 23 da International Organization for Standardization, utilizadas internacionalmente e adotada no Brasil em setembro de 2009 pela Portaria no 121/2009 do Ministério do Trabalho e Emprego 24 descrevem métodos para a avaliação dessas vestimentas em relação à repelência, permeação e penetração dos agrotóxicos. Como no Brasil não existem laboratórios credenciados pelo Ministério do Trabalho e do Emprego que realizem os ensaios para avaliação da eficácia na proteção durante as atividades com agrotóxico, é exigido apenas um termo de responsabilidade técnica 9,25. No Brasil, os estudos para avaliar a exposição e a proteção oferecida pelas vestimentas do EPI foram iniciados recentemente e têm sido de grande importância, uma vez que analisam as condições locais de exposição e podem auxiliar em normas e ensaios específicos de acordo com a necessidade do país 10 .

Considerando que as vestimentas de EPI utilizadas pelos agentes são trocadas apenas quando rasgadas, a exposição tende a se estender por um longo tempo, pois o ingrediente ativo fica retido. Outro fator em relação à retenção do ingrediente ativo a vestimenta e a contaminação do ambiente onde esse EPI é guardado e higienizado.

A vestimenta descartável apresentou baixa resistência física e fragilidade. Por ser um macacão os agentes encontraram dificuldade de mobilidade e a não possibilidade de descanso. Outro fator observado foi a disponibilidade de apenas 
um tamanho de macacão, que na maioria das vezes não é compatível com o peso e a altura do agente. Como na vestimenta reutilizável, o calor excessivo também foi observado no macacão o que pode favorecer a penetração da calda para o interior da roupa, aumentando a exposição do agente ao produto químico 13 .

\section{Resumen}

El insecticida malathion en jarabe aceitoso se utiliza en el control del Aedes aegypti y su aplicación se realiza través de un nebulizador. Esta actividad requiere el uso de un equipo de protección personal (PPE) para los fumigadores. Este estudio evaluó la capacidad de retención del insecticida malathion en la vestimenta del PPE. Se acompañó durante el proceso de nebulización en el campo a los agentes responsables de zoonosis en la ciudad de São Paulo, Brasil. Antes de cada nebulización se colocaron absorbentes debajo y encima de la ropa del PPE en el pecho, en la espalda y antebrazos. Después de cada aplicación, los absorbentes fueron identificados y sometidos a una extracción con agitación mecánica. Los extractos se analizaron por cromatografía de gases con detector de ionización de llama. Se observó la presencia de malathion en los absorbentes internos del PPE de la primera fumigación, antes de ser lavados. Los resultados indican que los agentes, en las condiciones evaluadas, están expuestos al malathion, incluso tras el uso de un PPE nuevo.

Equipos de Seguridad; Insecticidas Organofosforados; Aedes aegypti; Control de Vectores

\section{Conclusões}

Concluiu-se que as vestimentas do EPI utilizadas em campo possibilitaram a penetração de malationa, mesmo na primeira utilização antes de serem lavados, indicando que os trabalhadores mesmo utilizando a vestimenta não estão livres da exposição ao produto químico.

\section{Colaboradores}

T. S. Leme participou do desenvolvimento do trabalho e da redação do artigo. S. Papini colaborou na elaboração do artigo e na revisão crítica do conteúdo. E. Vieira contribuiu na aquisição, análise e interpretação dos dados e na concepção e redação do artigo. L. C. Luchini participou da revisão crítica e da aprovação da versão final a ser publicada.

\section{Agradecimentos}

À FAPESP (processos: auxílio à pesquisa - 09/52959-4 e bolsa de mestrado 10/03849-9). 


\section{Referências}

1. Superintendência de Controle de Endemias. Segurança em controle químico de vetores. http://su cen.sp.gov.br/atuac/dengue (acessado em 14/Jan/ 2010).

2. Papini S. Vigilância em saúde ambiental: uma nova era da ecologia. São Paulo: Editora Atheneu; 2008.

3. Guandalini S. Determinação de resíduos de pesticidas organofosforados em água superficiais através dos acoplamentos SPE-GC e SPME-GC [Dissertação de Mestrado]. São Carlos: Instituto de Química de São Carlos, Universidade de São Paulo; 1999.

4. Coordenação de Vigilância em Saúde de Campinas. Guia de intoxicações agudas por organofosforados (malation). http://2009.campinas.sp.gov.br/ saude/vigilancia/informes/intoxicaco_malation/ Guia_para_Intox_Agudas_Malation.pdf (acessado em 26/Jul/2011).

5. Vicino JRL. Extração em fase sólida de pesticidas organofosforados e organoclorados de matrizes aquosas [Dissertação de Mestrado]. São Carlos: Instituto de Física e Química de São Carlos, Universidade de São Paulo; 1993.

6. Extension Toxicology Network. Pesticides information profiles. http://extoxnet.orst.edu.pipis/mala thion (acessado em 14/Jan/2010).

7. Aragão MB, Amaral RS, Lima MM. Aplicação especial de inseticidas em saúde pública. Cad Saúde Pública 1988; 4:147-66.

8. Botti MV. Controle de Aedes aegypti: período residual de temefós na água em recipientes de plástico, vidro e borracha, ação larvicida residual em recipientes de borracha e segurança das condições de trabalho na nebulização de malathion [Tese de Doutorado]. Jaboticabal: Faculdade de Ciências Agrárias e Veterinárias, Universidade Estadual Paulista Júlio de Mesquita Filho; 2010.

9. Veiga MM, Duarte FJCM, Meirelles LA, Garrígou A, Baldi I. A contaminação por agrotóxicos e os equipamentos de proteção individual (EPIs). Rev Bras Saúde Ocup 2007; 32:57-68.

10. Garcia EG. Segurança e saúde no trabalho rural: a questão dos agrotóxicos. São Paulo: Fundação Jorge Duprat Figueiredo de Segurança e Medicina do Trabalho; 2001.

11. Peres F, Rozemberg B, Lucca SR. Percepção de riscos no trabalho rural em uma região agrícola do estado do Rio de Janeiro, Brasil: agrotóxicos, saúde e ambiente. Cad Saúde Pública 2005; 21:1836-44.

12. Fundação Nacional de Saúde. Dengue instruções para pessoal de combate ao vetor: manual de normas técnicas. 3a Ed. Brasília: Fundação Nacional de Saúde; 2001.

13. Garrígou A, Baldi I, Dubuc P. Contributos da ergotoxicologia na avaliação da eficácia real dos EPI que devem proteger do risco fitossanitário: da análise de contaminação ao processo coletivo de alerta. Laboreal 2008; IV:92-103.
14. Oliveira ML, Machado Neto JG. Segurança na aplicação de agrotóxicos em cultura de batata em regiões montanhosas. Rev Bras Saúde Ocup 2005; 30:15-25.

15. Davies JE, Freed VH, Enos HF, Duncan RC, Barquet A, Morgade C, et al. Reduction of pesticide exposure with protective clothing for applicators and mixers. J Occup Med 1982; 24:464-8.

16. Clifford NJ, Nies AS. Organophosphate poisoning from wearing a laundered uniform previously contaminated with parathion. JAMA 2989; 262:3035-6.

17. Tácio MB, Oliveira ML, Machado Neto JG. Eficiência de vestimentas hidrorepelente novas na proteção do tratorista em pulverizações de agrotóxicos em goiabas com o turbopulverizador. Rev Bras Frutic 2008; 30:106-11.

18. Souza RT. Uso de equipamentos de proteção individual na pulverização de videiras. Bento Gonçalves: Empresa Brasileira de Pesquisa Agropecuária; 2006. (Circular Técnica, 67).

19. Frenich AG, Aguilera PA, Gonzalez FE, Castro-Cano ML, Martinez-Galera M, Martinez-Vidal JL, et al. Dermal exposure to pesticides in greenhouses workers: discrimination and selection of variables for the design of monitoring programs. Environ Monit Assess 2002; 80:51-63.

20. Fundação Nacional de Saúde. Controle de vetores: procedimentos de segurança. Brasília: Fundação Nacional de Saúde; 2001.

21. Snograss HL. Permethrin transfer from treated cloth to the skin surface: potential for exposure in humans. J Toxicol Environ Health 1992; 35:91-105.

22. International Organization for Standardization. ISO 16602. Protective clothing for protection against chemicals: classification, labelling and performance requirements. Geneva: International Organization for Standardization; 2007.

23. International Organization for Standardization. ISO 27065. Protective clothing: performance requirements for protective clothing worn by operators applying liquid pesticides. Geneva: International Organization for Standardization; 2011.

24 Ministério do Trabalho e Emprego. Portaria no 3.214, de 8 de junho de 1978. Aprova as Normas Regulamentadoras - NR - do Capítulo V, Título II, da Consolidação das Leis do Trabalho, relativas à segurança e medicina do trabalho. Norma Regulamentadora Equipamento de Proteção Individual - NR 6. Diário Oficial da República Federativa do Brasil 1978; 6 jul.

25. Francischini LASN. Classificação e eficiência de materiais e de Vestimentas de proteção no trabalho com agrotóxicos [Tese de Doutorado]. Jaboticabal: Faculdade de Ciências Agrárias e Veterinárias, Universidade Estadual Paulista Júlio de Mesquita Filho; 2009.

Recebido em 01/Out/2012

Versão final reapresentada em 22/Ago/2013

Aprovado em 12/Set/2013 